INTERNATIONAL HIGHER EDUCATION, Number 73 Fall 2013

Pages 21-23

\title{
The Founding of University of Chinese Academy of Sciences
}

\author{
QIANG ZHA and GUANGLI ZHOU
}

Qiang Zha is an associate professor at the Faculty of Education, York University, Toronto, Canada. E-mail: qzha@edu.yorku.ca. Guangli Zhou is a professor at the School of Education, Renmin University, Beijing, China. E-mail: guanglizhou@ruc.edu.cn.

Following the Soviet model, Chinese Academy of Sciences (CAS) was founded in November 1949, as a landmark of China's research and development ( $R$ \& D) system. The CAS, together with Chinese Academy of Engineering and Chinese Academy of Social Sciences (both grown out of former divisions within the CAS), stand for China's top research organizations, forming a separate research system from the university sector and equipped with the best research resources. The founding of University of Chinese Academy of Sciences (UCAS) in July 2012, on the basis of former Graduate School of the Chinese Academy of Sciences (GSCAS), should be viewed as a meaningful event occurring in China's R \& D system, and in the university sector. As such, the UCAS was born with "a silver spoon." It shares a president with the CAS, and its program offering areas and school/college arrangements match well with the six academic divisions of the latter system. 
Among its 10,599 faculty are 282 CAS members (out of a total of 694 across the country) and 5,335 doctoral student supervisors. These figures far exceed those of Tsinghua University (currently having 41 CAS members, 1,832 doctoral student supervisors, and 9,357 doctoral enrollment) and Peking University (now with 63 CAS members, around 1,700 doctoral supervisors, and approximately 7,000 doctoral students), the two most prestigious universities so far in China. Though the UCAS will not open its door to undergraduates until fall 2013, it has inherited nearly 40,000 graduate students from the GSCAS, among whom one half are doctoral students. In 2011 alone, the UCAS—while still under the name of the GSCAS—conferred 4,832 doctoral degrees. This figure itself would enable the UCAS to sit on the top category in the Carnegie Classification and to beat even those most fertile American campuses in terms of producing doctorates. With the founding of the UCAS, China seems to have had a world-class university overnight. At this point, a question is naturally raised: why does the CAS make this move, which seems to have turned itself into a university? Furthermore, is the founding of the UCAS an isolated story or a prelude to something more significant?

\section{The Support for Research in Chinese Universities}

There have long been discussions and debates with respect to reforming China's $\mathrm{R} \& \mathrm{D}$ system, in particular surrounding the CAS. Ever since its founding, the CAS is mandated as to "defining scientific research orientations" and "outlining strategies for the nation's future scientific and technological development," while devoting itself to accomplishing research projects. As such, it plays a combined role of the nation's supreme R \& D advisory body and the national flagship R \& 
D center in sciences and technologies. However, ever since China started to boost research in universities in the mid-1990s, through launching a series of elite university schemes (i.e., Projects 211 and 985), there has been an increasing wish to optimize the country's R \& D system and using universities as the backbone for basic research.

In a 2009 article, the former president of Peking University, Xu Zhihong (who is himself a CAS member) argues the state should recognize the predominant status of research-intensive universities, citing such advantage of universities over research institutes as concentration of researchers, integration of research and education, comprehensiveness of programs and subjects, and collegial ethos. He asserts those advantages are crucial not only for basic research but also for applied research, which now increasingly requires a multidisciplinary approach. He benchmarks the key research performance and outcomes of 10 Project 985 universities, against those of the CAS between 2004 and 2008, and affirms their combined research strength has outmatched the CAS. Notably, China now has 1,129 universities, including 112 research-intensive ones that are selected on Projects 985 and 211. In 2007, universities produced 84.6 percent of China's research papers that were published in international sources.

Some other universities adopt more critical tones toward the CAS's bureaucratic and less efficient style, suggesting to regenerate it following the model of the French Centre National de la Recherche Scientifique or the US National Academy of Sciences-to align it with a science and technology policy advisory role as well as a supreme honor society, while most of its subordinate research institutes should be delegated to universities. The CAS has been argued as a legacy of the planned economy and a role as both the nation's supreme 
science and technology advisory body and executing arm of the key research projects, putting itself in a controversial and awkward quandary. Furthermore, especially basic research can hardly attain breakthroughs under a planned regime. Notably, such contentions are often echoed in a socioeconomic context, where the higher education patterns have already shifted away from the Soviet model and toward the American one.

The National Outline for Medium- and Long-Term Science and Technology Development (2006-2020) fully recognizes universities as "a principal player in basic research and original technology innovation," and sees the "establishment of high caliber universities, particularly world-class research universities" as "a prerequisite for enhancing the nation's S\&T innovation and instituting a national innovation system." Following this initiative, the Chinese government launched Project 2011 in early 2012, which exclusively supports universities to expand their research and innovation capacity, through integrative collaborations with research institutes and industry. Most recently, the Opinions on Deepening Science and Technology Structural Reform and Accelerating the Making of National Innovation System (released in September 2012) promulgates a policy to turn industry into a major R \& D spender and the backbone of technological innovation (like Boeing, Lockheed Martin, Microsoft, or Pfizer in the United States), while maintaining to push for world-class research universities in China's effort to optimize its R \& D system. Indeed, in 2011, China's industry contributed 74 percent to the country's R \& D spending. Against this backdrop, the founding of the UCAS appears to affirm an ongoing shift of China's R \& D focus to the university sector. 


\section{What Is COMING NeXt?}

Following the UCAS, a brand new Shanghai Tech University was founded in January 2013, which is also patronized by the CAS (and the Shanghai municipal government). The academic areas of this university's program offerings correspond with those of the research institutes of the CAS Shanghai Branch. Also, it shares an executive head with the latter. The possibility could never be ruled out that more universities of this type (or spin-off versions) would come forth. Therefore, a preliminary conclusion could be drawn at this point that, if the role of the CAS as a research executing entity is coming to an end soon and its subordinate institutes are going to universities, Chinese universities will enjoy a great leap in terms of their research capacity and conditions. After all, the CAS had an annual research expenditure of $\$ 3.6$ billion, over 100 national key laboratories, and 45,400 researchers (all figures as of 2010). If the CAS stays as is

(for a short while or a longer term), China would probably see an expanding list of its star research universities, and many other Chinese universities would benefit from their growing and closer collaborations with the CAS research institutes, which is boosted by China's new policy initiatives and double-digit $R$ \& D funding increases. 